\title{
Soft tissue sarcomas in the precision medicine era: new advances in clinical practice and future perspectives
}

\author{
Giuseppe Badalamenti ${ }^{1}$. Carlo Messina ${ }^{2,3} \cdot$ Ida De Luca $^{1} \cdot$ Emmanuela Musso $^{1}$ - Alessandra Casarin ${ }^{1}$. \\ Lorena Incorvaia ${ }^{1}$
}

Received: 20 February 2018 / Accepted: 29 March 2018 / Published online: 4 April 2018

(c) Italian Society of Medical Radiology 2018

\begin{abstract}
Soft tissue sarcomas (STSs) represent a rare and heterogeneous group of solid tumours derived from mesenchymal progenitors and account for $1 \%$ of all adult malignancies. Although in the last decade anthracycline-based chemotherapy single agent or in combinations has been able to improve clinical benefits, prognosis is still poor and STSs represent an important unmet medical need. Continuous advances in cancer genetics and genomics have contributed to change management paradigms of STSs as it occurred for other solid tumours. Several treatments have been recently developed with the specific aim of targeting different cell pathways and immune-checkpoints that have been recognized to drive tumour progression. The following attempts to provide a review of literature focusing on the available data concerning novel treatments and future prospective for the management of metastatic STSs.
\end{abstract}

Keywords Soft tissue sarcomas $\cdot$ Immune-checkpoint inhibitors $\cdot$ Pembrolizumab $\cdot$ Eribulin $\cdot$ Olaratumab $\cdot$ Targeted therapy

\section{Introduction}

Soft tissue sarcomas (STSs) represent a rare and heterogeneous group of solid tumours derived from mesenchymal progenitors and account for $1 \%$ of all adult malignancies [1]. Approximately $80 \%$ of sarcomas arise from soft tissue and viscera, whereas the remaining $20 \%$ originate from bone. STSs potentially may occur at all body anatomic sites, even though the majority arise from the extremities. An observational study of the American College of Surgeons showed that among a cohort of 4550 patients suffering from sarcomas, $46 \%$ originate from thigh, buttock and groin, $13 \%$ by

Giuseppe Badalamenti

giuseppe.badalamenti@unipa.it

1 Section of Medical Oncology, Department of Surgical, Oncological, and Oral Sciences, University of Palermo, Palermo, Italy

2 Academic Unit of Medical Oncology, Institute for Cancer Treatment and Research, Policlinico Hospital San Martino, Genoa, Italy

3 Department of Internal Medicine, School of Medicine, University of Genoa, Genoa, Italy upper extremities, $18 \%$ torso, $13 \%$ retroperitoneum and $9 \%$ head and neck [2].

As classified by the World Health Organization (WHO), the group of STSs comprise more than 100 different histologies according to the presumptive tissue in origin [3]. Histological diagnosis is crucial to define staging, prognosis and to deliver appropriate therapy. Unfortunately, sometimes it causes a diagnostic challenge for pathologist, particularly when the diagnostic material is a small biopsy and when clinical information is incomplete. Although in the past STSs were considered a whole entity and treated similarly, consensus is emerging that the choice of treatment for advanced disease should be histology driven. After the development of distant metastasis the median overall survival (OS) is 12-19 months, and almost $20 \%$ of patients are still alive at 3 years [4]. Systemic therapy provides palliation and prolongs survival for patients with metastatic or unresectable STSs. For patients with a good performance status and STS histology that is known to have sensitivity to anthracyclines (liposarcoma, leiomyosarcoma, synovial sarcoma, pleomorphic or undifferentiated sarcoma, malignant nerve sheath tumour, angiosarcoma), anthracyclinebased chemotherapy represents the standard of care for first-line setting [5]. For patients ineligible to anthracycline 
combination due to a poor performance status or extensive comorbidity, pegylated liposomal doxorubicin, gemcitabine alone or in combination and dacarbazine are reasonable options [6-8]. A histology-driven approach should be regarded for patients who progressed after first-line therapy. Weekly paclitaxel seems to be useful for advanced angiosarcomas [9]; synovial sarcomas are sensitive to alkylating agents as ifosfamide [10]; sunitinib appears to be active in patients with solitary fibrous tumour and alveolar sarcoma, clear cell sarcoma and extra-skeletal myxoid chondrosarcoma [11-13]; gemcitabine plus docetaxel regimen is active on uterine leiomyosarcomas [14]. Trabectedin is approved for the treatment of leiomyosarcomas and liposarcomas previously treated with anthracycline-based chemotherapy [15]. Pazopanib might be considered for STSs other than liposarcomas for patients progressing on first-line chemotherapy (including anthracyclines) [16].

Although these treatments or chemotherapy combinations have been able to improve clinical benefits, prognosis is still poor and STSs represent an important unmet medical need.

Continuous advances in cancer genetics and genomics have contributed to change management paradigms of STSs as it occurred for other solid tumours. Several treatments have been recently developed with the specific aim of targeting different cell pathways and immune-checkpoints that have been recognized to drive tumour progression (Table 1). The following attempts to provide a review of literature focusing on the available data concerning novel treatments and future prospective for the management of metastatic STSs.

\section{Methods}

A literature search using PubMed was carried out with no date restriction up to November 2017. The search strategy has included the keywords "soft tissue sarcomas", "Olaratumab", "Eribulin", "immune-checkpoint", "targeted therapy". A computerized search of the abstracts reported at ASCO and ESMO library, and the clinical trial database on the website http://www.clinicaltrial.gov was performed to identify relevant unpublished studies and ongoing trials. Finally, a crosscheck references from review articles and relevant studies on the same topic were performed to confirm retrieval of all pertinent trials.

Eligible studies had to fulfil the following criteria: randomized prospective phase II-III trial assessing new or recently approved treatments for patients with metastatic STSs.

Table 1 Main characteristics of clinical trials carried out on metastatic STS patients

\begin{tabular}{|c|c|c|c|c|c|c|}
\hline Clinical trial & Drug & Histological type & Study design & Primary endpoint & N. patients & Results \\
\hline Tap et al. [21] & $\begin{array}{l}\text { Olaratumab + doxoru- } \\
\text { bicin vs doxorubicin }\end{array}$ & $\begin{array}{l}\text { LMS, UPS, LS, AS, } \\
\text { SS, NFS, F, other }\end{array}$ & PHASE Ib/II & PFS & 133 & $\begin{array}{l}\text { mPFS: } 6.6 \text { vs } \\
4.1 \text { months } \\
(p=0.0615) \\
\text { mOS: } 26.5 \text { vs } \\
14.7 \text { months } \\
(p=0.0003) \\
\text { ORR: } 18.2 \text { vs } 11.9 \% \\
(p=0.3421)\end{array}$ \\
\hline Wagner et al. [26] & Olaratumab & $\begin{array}{l}\text { GISTs previously } \\
\text { treated with a TKI }\end{array}$ & PHASE II & $\begin{array}{l}\text { 12-week tumour } \\
\text { response }\end{array}$ & 30 & $\begin{array}{l}\text { 12-week tumour } \\
\text { response: } 50 \% \text { of } \\
\text { SD at } 12 \text {-week in } \\
\text { PDGFR } \alpha \text { mutant } \\
\text { patients vs } 14.3 \% \\
\text { in PDGFR } \alpha \text { nega- } \\
\text { tive }\end{array}$ \\
\hline Schöffski et al. [31] & Eribulin & LMS, SS, LS, other & PHASE II & 12-weeks PFS & 128 & $\begin{array}{c}\text { 12-week PFS: } 46.9 \% \\
\text { LMS vs } 31.6 \% \text { LS }\end{array}$ \\
\hline Schöffski et al. [32] & $\begin{array}{l}\text { Eribulin vs dacar- } \\
\text { bazine }\end{array}$ & LS, LMS & PHASE III & OS & 452 & $\begin{array}{l}\text { mOS: } 13.5 \text { vs } \\
11.5 \text { months } \\
(p=0.0169) \\
\text { mPFS: } 2.6 \text { vs } 2.6 \\
\text { months }(p=0.23)\end{array}$ \\
\hline Tawbi et al. [38] & Pembrolizumab & $\begin{array}{l}\text { LS, LMS, ES, SS, PS, } \\
\text { CS, OST }\end{array}$ & PHASE II & PFS & 84 & $\begin{array}{l}\text { ORR: PS: } 40 \text { vs LS: } \\
20 \% \text {, SS: } 10 \%\end{array}$ \\
\hline
\end{tabular}

LMS leiomyosarcoma, UPS undifferentiated pleomorphic sarcoma, $L S$ liposarcoma, $A S$ angiosarcoma, $S S$ synovial sarcoma, NFS neurofibrosarcoma, $F$ fibrosarcoma, ES Ewing's sarcoma, PS pleomorphic sarcoma, CS chondrosarcoma, $O S T$ osteosarcoma, TKI tyrosine kinase inhibitor, (m) OS (median)overall survival, $(m) P F S$ (median) progression-free survival, $O R R$ objective response rate 
Retrospective studies and case reports were excluded from the analysis. No language restriction was applied.

\section{Olaratumab}

Platelet-derived growth factor (PDGF) and PDGF receptor (PDGFR) are key regulators of oncogenesis process in many solid tumours, including mesenchymal stem cell differentiation, angiogenesis and tumour growth [17]. Several studies in vitro and in animal models showed that PDGFR $\alpha$ inhibition leads to an arrest of tumour proliferation and spread [18]. Olaratumab is a human monoclonal antibody (IgG1) that binding PDGFR $\alpha$ results in an inhibition of receptor autophosphorylation and downstream signalling [19]. Olaratumab alone or in combination with doxorubicin showed antitumor activities in human sarcoma xenograft models [20].

Basing on these data and rationale, an open-label phase Ib/II trial randomized 133 patients with histologically confirmed STSs diagnosis to receive olaratumab $15 \mathrm{mg} / \mathrm{kg}$ on day 1 and 8 plus doxorubicin $75 \mathrm{mg} / \mathrm{m}^{2}$ day 1 three-weekly or doxorubicin alone [21]. Detection of a $50 \%$ improvement in progression-free survival (PFS) in the combination arm was the primary endpoint of the study. The proportion of leiomyosarcomas patients was well balanced between the two arms (36.4\% versus $40.3 \%$ in experimental arm and doxorubicin arm, respectively). The median PFS was 6.6 months for patients treated with Olaratumab plus doxorubicin and 4.1 months for those under treatment with doxorubicin alone (HR 0.67, CI 95\% 0.44-1.02, $p$ 0.0615). This improvement met the protocol-defined significance level of 0.19 . The independent review assessment showed similarly an advantage in favour of combination arm compared to control arm (8.2 versus 4.4 months, respectively, HR 0.67, CI 95\% 0.40-1.12, $p=0.0003)$. The objective response rate was slightly higher for olaratumab plus doxorubicin than doxorubicin alone (18.2 versus $11.9 \%, p=0.3421)$. Final analysis showed a significantly better $\mathrm{OS}$ for patients treated with the combination than doxorubicin alone (26.5 versus 14.7 months, respectively, HR 0.46, CI 95\% 0.30-0.71). This achievement was consistent across the subgroup analysis including PDGFR $\alpha$ status, histological subtypes (leiomyosarcoma versus nonleiomyosarcoma) and number of previous treatments $(0$ versus $\geq 1)$. Infusion-related reaction $(3 \%)$ was the main cause leading to Olaratumab discontinuation, whereas $5 \%$ of ejection-fraction decrease was the most common reason of discontinuation in doxorubicin group. Grade 3-4 occurred more frequently in the doxorubicin and olaratumab arm than in doxorubicin alone arm (42-31\%). The most common adverse events in the combination arm include neutropenia, nausea, fatigue, vomiting and mucositis [21].

Despite clinical trial limitation due to the small sample size and heterogeneity of STSs histology, this finding is particularly notable given the little progress in improvement of median OS achieved for patients suffering from metastatic STSs. In a phase III trial, the combination doxorubicin plus high dose of ifosfamide improved PFS and response rate compared with doxorubicin alone in first-line therapy. However, this small benefit was achieved at expense of higher toxicities without any improvement in median OS (HR 0.83 , $p=0.76$ ) [22]. Therefore, the promising results of the randomized phase II trial lead FDA in October 2016 and EMA in November 2016 to the rapid approval of the combination olaratumab plus doxorubicin. Many ongoing clinical trials are assessing the activity of Olaratumab alone or in combination with chemotherapy regimen.

A randomized double-blind phase III ANNOUNCE trial is still recruiting 460 patients with advanced or metastatic STSs to receive olaratumab $15 \mathrm{mg} / \mathrm{kg}$ on day 1 and 8 plus doxorubicin $75 \mathrm{mg} / \mathrm{m}^{2}$ on day 1 every 3 weeks versus doxorubicin $75 \mathrm{mg} / \mathrm{m}^{2}$ plus placebo (NCT02451943). OS in whole population and in patients with leiomyosarcoma are the two primary objectives of the study.

A phase Ib trial (NCT02783599) is recruiting potentially 40 patients to receive Olaratumab $20 \mathrm{mg} / \mathrm{m}^{2}$ alone for day 1 and 8 of the first cycle, then olaratumab $20 \mathrm{mg} / \mathrm{m}^{2}$ in combination with doxorubicin $75 \mathrm{mg} / \mathrm{m}^{2}$ for the second cycle and then olaratumab $15 \mathrm{mg} / \mathrm{m}^{2}$ on the same schedule alongside doxorubicin for the third cycle. The primary endpoint was to molecularly characterize the circulating tumour cell pre- and post-olaratumab, and to analyze PDGFR $\alpha$, PDGFR $\beta$, and PDGF ligand changes.

A phase Ib/II (NCT02659020) trial is enrolling patients with metastatic STSs to assess safety, activity and efficacy of olaratumab in combination with gemcitabine and docetaxel. Dose finding to carry out a phase II trial was the primary endpoint. The phase II trial will randomly assign patients with metastatic STSs to receive olaratumab in combination of gemcitabine plus docetaxel or gemcitabine plus docetaxel and placebo. OS is the primary endpoint.

An open-label phase I trial (NCT03126591) is recruiting patients with metastatic STSs who has progressed to standard treatment to receive olaratumab plus pembrolizumab. Dose-limiting toxicity is the primary endpoint.

Most gastrointestinal tumours (GISTs) are driven by activating mutation in KIT tyrosine kinase receptor [23]. Although $80-90 \%$ of GISTs harbour KIT expression, some are not. This finding may be partially explained by the occurrence of activating mutation in the gene encoding the PDGFR $\alpha$ [24].

Most GISTs harbouring PDGFR $\alpha$ are primarily resistant to standard therapy due to D842V mutation that leads tumours not to be inhibited by approved treatments [25]. Given the benefits achieved by olaratumab targeting PDGFR $\alpha$ in preclinical models [20], a phase II trial evaluated tumour response to olaratumab in 30 previously treated 
metastatic GISTs into two cohorts with or without PDGFR $\alpha$ mutations, respectively [26]. Twelve-week tumour response, PFS, OS and safety were outcome measures.

Although no objective disease responses were observed in the two cohorts, metastatic PDGFR $\alpha$ GISTs significantly experienced longer median PFS (32.1 and 6.1 weeks) and OS (NR and 24.9 weeks) than PDGFR $\alpha$ negative. Fatigue, abdominal pain, constipation, nausea, and headache were the most common related adverse events. Despite the limitation of this trial due to small sample size and inter-study heterogeneity to draw a definitive conclusion, these data provide the rationale for further study of PDGFR $\alpha$-mutant GIST in larger study [26].

\section{Eribulin}

Eribulin, originally isolated from the marine sponge Halichondria Okadai, is a structurally modified analogue of halichondrin B. Eribulin's antitumor activity is due to microtubule dynamics inhibition. Irreversible binding of specific sites on the growing plus ends of microtubules results in the arrest of cancer cell growth and apoptosis via prometaphase blockage [27]. Moreover, Eribulin seems also to inhibit Wnt/ $\beta$-catenin signalling, alter tumour vascularization resulting in higher perfusion and drug delivery, and reverse the epithelial to mesenchymal transition [28, 29]. Eribulin has been approved as standard of care for women with advanced or metastatic breast cancer who progressed after previous chemotherapy regimen [30]. Given Eribulin's antitumor activity in preclinical xenograft models of leiomyosarcomas and fibrosarcomas, a non-randomized phase II (study 17) trial assessed the activity and safety of Eribulin $1.4 \mathrm{mg} / \mathrm{m}^{2}$ administered intravenously on days 1 and 8 every 3 weeks in four independent strata of 128 patients with mesenchymal tumours (leiomyosarcoma, liposarcoma, synovial sarcoma and other defined STS) [31]. PFS at 12 weeks was the primary endpoint. Activity was demonstrated in patients with liposarcoma (46.9\% PFS at 12 weeks, 95\% CI 29.1-65.3\%) and leiomyosarcoma (31.6\% PFS at 12 weeks, 95\% CI 17.6-48.7\%) [31].

An open-label phase III trial (study 309) randomly assigned 458 patients with metastatic intermediate or high-grade liposarcoma and leiomyosarcoma previously progressed on anthracycline-based chemotherapy to receive Eribulin $1.4 \mathrm{mg} / \mathrm{m}^{2}$ day 1 and 8 or dacarbazine $850-1200 \mathrm{mg} / \mathrm{m}^{2}$ every 21 days until disease progression or unacceptable toxicities [32]. OS was the primary endpoint. Eribulin significantly prolonged OS in whole population compared to dacarbazine (13.5 versus 11.5 months, HR $0.77,95 \%$ CI 0.62-0.95), although PFS was similar in both arms (2.6 versus 2.6 moths HR $0.88,95 \%$ CI $0.71-1.09$, $p=0.23$ ) [32]. In a pre-planned specific-histology subgroup analysis, benefits for eribulin were limited to patients with liposarcoma (median OS 15.6 versus 8.4 months, HR $0.51,95 \%$ CI $0.35-0.75, p<0.001$ ), and the improvement in OS was observed in all histologic liposarcoma subtypes [33]. PFS was also improved with Eribulin versus dacarbazine (2.9 versus 1.7 months, HR $0.52,95 \%$ CI $0.35-0.78$, $p=0.0015)$ [33]. Most common adverse events with Eribulin included neutropenia (43 versus $24 \%$ ), pyrexia (28 versus $14 \%$ ), alopecia (35 versus $3 \%$ ) and peripheral sensory neuropathy [32].

Basing on these results, Eribulin has been approved in the USA and Europe for treatment of metastatic liposarcoma for patients who received prior anthracycline-based chemotherapy.

An ongoing single-arm (NCT03331250) phase II trial aims to assess the activity and effectiveness of Eribulin $1.4 \mathrm{mg} / \mathrm{m}^{2}$ on day 1 and 8 administered intravenously threeweekly in patients with unresectable or metastatic angiosarcoma and hemangioendothelioma treated with at least one prior systemic treatment. Objective response rate is the primary endpoint, whereas PFS, disease control rate and treatment-related adverse events are the secondary endpoints. Primary completion date is estimated for May 31, 2021.

\section{Immune-checkpoint inhibitors}

Although the approval in the last decade of several drugs for the treatment of metastatic STSs $[15,16]$, these therapies did not achieve a substantial cure rate, leading to the development of new agents.

Response to conventional radiotherapy or chemotherapy is dependent on histology because some subtypes are chemo-resistant.

Cancer immunotherapy is gradually taking on a key role in the management of metastatic solid tumours, preventing the development of resistant clones to traditional chemotherapy and fostering tumour recognition by the immune system [34]. Historically, studies using cytokines or immune adjuvants provided small benefits for patients with metastatic STSs [35, 36].

In a randomized phase III trial, immunotherapy with adjuvant mifamurtide, a nonspecific immune stimulator, improves OS in patients with osteosarcoma [37]. Recently, the appeal for the improved clinical benefits in several solid tumours due to immune-checkpoint inhibitors leads to assess the safety and activity of these agents in STSs.

A two-cohort, single-arm, open-label phase II trial (SARC028) enrolled 84 patients with metastatic or unresectable STSs (leiomyosarcoma, poorly differentiated or dedifferentiated liposarcoma, Ewing's sarcoma, synovial sarcoma, undifferentiated pleomorphic osteosarcoma, dedifferentiated or mesenchymal chondrosarcoma) previously progressed up to three lines of chemotherapy to receive pembrolizumab $200 \mathrm{mg}$ intravenously every 3 weeks until 
progression or unacceptable toxicities [38]. Objective response was the primary endpoint. Almost $18 \%$ of patients with STSs had a clinically meaningful objective response, including $40 \%$ with undifferentiated pleomorphic sarcoma, $20 \%$ with liposarcoma, $10 \%$ with synovial sarcoma, and 5\% with osteosarcoma. No patients with leiomyosarcoma had an objective response.

This result is consistent with data from a phase II trial on nivolumab in leiomyosarcomas that was stopped early because of futility, suggesting a detrimental effect of antiPD1 single agent in this subset of patients [39]. Although the mechanism of immune resistance related to leiomyosarcoma histology is still unclear, PTEN loss and PI3K pathway may play a key role in this process [40]. A partial response was observed only in one patient with Ewing's sarcoma, suggesting that a small subset of patients suffering from this rare tumour may benefit from single-agent pembrolizumab.

The 12-week PFS was 55\% (95\% CI 40-70), which was significantly higher than the threshold of $40 \%$ expected for an active treatment for patients with STSs $(p=0.039)$. Most common adverse events were anaemia, decreased lymphocyte count and platelet count in the bone sarcoma group, whereas anaemia decreased lymphocyte count and prolonged activated partial thromboplastin time in the STSs group.

In an open-label multicentre phase II trial, 85 patients with metastatic STSs or osteosarcoma previously treated with standard chemotherapies were randomized to receive the anti-PD1 monoclonal antibody nivolumab with or without the anti-CTLA4 ipilimumab [41]. In a preliminary analysis reported at ASCO 2017 annual meeting, the combination nivolumab plus ipilimumab provided encouraging antitumor activities due to six confirmed responses in 38 treated patients and a median PFS of 4.5 months [41].

Given that none of these immune-checkpoint inhibitors is approved for advanced sarcomas, appropriately selected patients should be referred for clinical trials exploring these strategies. Many ongoing trials are still recruiting patients with metastatic STSs to assess the activity and efficacy of immune-checkpoint inhibitors in metastatic settings in combination with chemotherapy or neoadjuvant setting with radiotherapy (NCT03092323, NCT03092323, NCT03307616). Briefly, several ongoing phase I/II clinical trials are exploring the activity of pembrolizumab in combination with doxorubicin (NCT02888665, NCT03056001), axitinib (NCT02636725), olaratumab (NCT03126591). Dose finding, safety and objective response represent the main endpoint of these trials. Similarly, several ongoing phase I/II trials are assessing safety and tolerability of nivolumab single agent (NCT03316274) or in combination with Pazopanib (NCT03149120), ipilimumab (NCT03219671, NCT02982486, NCT02500797, NCT02304458, NCT02428192).

\section{Conclusion}

Histology-driven approach still remains the mainstay for the treatment of advanced unresectable or metastatic STSs. Although the utmost efforts in the development and quick approval of novel active and practice changing drugs $[15,16,21,32]$, prognosis is still poor [4]. Patients with advanced unresectable or metastatic STSs are ideal candidates for clinical trials to identify new prognostic and predictive factors of response to better select patients to maximize the effectiveness of more active single agents, combinations, or novel approaches.

Funding None.

\section{Compliance with ethical standards}

Conflict of interest All authors declare no conflicts of interest.

Ethical approval This article does not contain any studies with animals or humans performed by any of the authors.

\section{References}

1. Siegel RL, Miller KD, Jemal A (2017) Cancer statistics, 2017. CA Cancer J Clin 67(1):7-30

2. Lawrence W Jr, Donegan WL, Natarajan N, Mettlin C, Beart R, Winchester D (1987) Adult soft tissue sarcomas. A pattern of care survey of the American College of Surgeons. Ann Surg 205(4):349-359

3. Jo VY, Fletcher CD (2014) WHO classification of soft tissue tumours: an update based on the 2013 (4th) edition. Pathology 46(2):95-104

4. Judson I, Verweij J, Gelderblom H, Hartmann JT, Schöffski P, Blay JY, Kerst JM, Sufliarsky J, Whelan J, Hohenberger P, Krarup-Hansen A, Alcindor T, Marreaud S, Litière S, Hermans C, Fisher C, Hogendoorn PC, dei Tos AP, van der Graaf WT, European Organisation and Treatment of Cancer Soft Tissue and Bone Sarcoma Group (2014) Doxorubicin alone versus intensified doxorubicin plus ifosfamide for first-line treatment of advanced or metastatic soft-tissue sarcoma: a randomised controlled phase 3 trial. Lancet Oncol 15(4):415-423

5. Mouridsen HT, Bastholt L, Somers R, Santoro A, Bramwell V, Mulder JH, van Oosterom AT, Buesa J, Pinedo HM, Thomas $D$ et al (1987) Adriamycin versus epirubicin in advanced soft tissue sarcomas. A randomized phase II/phase III study of the EORTC Soft Tissue and Bone Sarcoma Group. Eur J Cancer Clin Oncol 23(10):1477-1483

6. Gottlieb JA, Benjamin RS, Baker LH, O'Bryan RM, Sinkovics JG, Hoogstraten B, Quagliana JM, Rivkin SE, Bodey GP Sr, Rodriguez V, Blumenschein GR, Saiki JH, Coltman C Jr, Burgess MA, Sullivan P, Thigpen T, Bottomley R, Balcerzak S, Moon TE (1976) Role of DTIC (NSC-45388) in the chemotherapy of sarcomas. Cancer Treat Rep 60(2):199-203

7. Merimsky O, Meller I, Flusser G, Kollender Y, Issakov J, WeilBen-Arush M, Fenig E, Neuman G, Sapir D, Ariad S, Inbar M (2000) Gemcitabine in soft tissue or bone sarcoma resistant to 
standard chemotherapy: a phase II study. Cancer Chemother Pharmacol 45(2):177-181

8. Judson I, Radford JA, Harris M, Blay JY, van Hoesel Q, le Cesne A, van Oosterom AT, Clemons MJ, Kamby C, Hermans C, Whittaker J, Donato di Paola E, Verweij J, Nielsen S (2001) Randomised phase II trial of pegylated liposomal doxorubicin (DOXIL/CAELYX) versus doxorubicin in the treatment of advanced or metastatic soft tissue sarcoma: a study by the EORTC Soft Tissue and Bone Sarcoma Group. Eur J Cancer 37(7):870-877

9. Fury MG, Antonescu CR, Van Zee KJ, Brennan MF, Maki RG (2005) A 14-year retrospective review of angiosarcoma: clinical characteristics, prognostic factors, and treatment outcomes with surgery and chemotherapy. Cancer J 11(3):241-247

10. Vlenterie M, Litière $S$, Rizzo E, Marréaud S, Judson I, Gelderblom H, Le Cesne A, Wardelmann E, Messiou C, Gronchi A, van der Graaf WT (2016) Outcome of chemotherapy in advanced synovial sarcoma patients: review of 15 clinical trials from the European Organisation for Research and Treatment of Cancer Soft Tissue and Bone Sarcoma Group; setting a new landmark for studies in this entity. Eur J Cancer 58:62-72

11. George S, Merriam P, Maki RG, Van den Abbeele AD, Yap JT, Akhurst T, Harmon DC, Bhuchar G, O'Mara MM, D'Adamo DR, Morgan J, Schwartz GK, Wagner AJ, Butrynski JE, Demetri GD, Keohan ML (2009) Multicenter phase II trial of sunitinib in the treatment of nongastrointestinal stromal tumor sarcomas. J Clin Oncol 27(19):3154-3160

12. Stacchiotti S, Negri T, Libertini M, Palassini E, Marrari A, De Troia B, Gronchi A, Dei Tos AP, Morosi C, Messina A, Pilotti S, Casali PG (2012) Sunitinib malate in solitary fibrous tumor (SFT). Ann Oncol 23(12):3171-3179

13. Stacchiotti S, Pantaleo MA, Astolfi A, Dagrada GP, Negri T, Dei Tos AP, Indio V, Morosi C, Gronchi A, Colombo C, Conca E, Toffolatti L, Tazzari M, Crippa F, Maestro R, Pilotti S, Casali PG (2014) Activity of sunitinib in extraskeletal myxoid chondrosarcoma. Eur J Cancer 50(9):1657-1664

14. Hensley ML, Maki R, Venkatraman E, Geller G, Lovegren M, Aghajanian C, Sabbatini P, Tong W, Barakat R, Spriggs DR (2002) Gemcitabine and docetaxel in patients with unresectable leiomyosarcoma: results of a phase II trial. J Clin Oncol 20(12):2824-2831

15. Kawai A, Araki N, Sugiura H, Ueda T, Yonemoto T, Takahashi M, Morioka H, Hiraga H, Hiruma T, Kunisada T, Matsumine A, Tanase T, Hasegawa T, Takahashi S (2015) Trabectedin monotherapy after standard chemotherapy versus best supportive care in patients with advanced, translocation-related sarcoma: a randomised, open-label, phase 2 study. Lancet Oncol 16(4):406-416

16. Sleijfer S, Ray-Coquard I, Papai Z, Le Cesne A, Scurr M, Schöffski P, Collin F, Pandite L, Marreaud S, De Brauwer A, van Glabbeke M, Verweij J, Blay JY (2009) Pazopanib, a multikinase angiogenesis inhibitor, in patients with relapsed or refractory advanced soft tissue sarcoma: a phase II study from the European organisation for research and treatment of cancer-soft tissue and bone sarcoma group (EORTC study 62043). J Clin Oncol 27(19):3126-3132

17. Ng F, Boucher S, Koh S, Sastry KS, Chase L, Lakshmipathy U, Choong C, Yang Z, Vemuri MC, Rao MS, Tanavde V (2008) PDGF, TGF-beta, and FGF signaling is important for differentiation and growth of mesenchymal stem cells (MSCs): transcriptional profiling can identify markers and signaling pathways important in differentiation of MSCs into adipogenic, chondrogenic, and osteogenic lineages. Blood 112(2):295-307

18. Li C, Wang Y, Lu S, Zhang Z, Meng H, Liang L, Zhang Y, Song B (2015) MiR-34a inhibits colon cancer proliferation and metastasis by inhibiting platelet-derived growth factor receptor $\alpha$. Mol Med Rep 12(5):7072-7078
19. Zhang Z, Ren X, Lu X, Wang D, Hu X, Zheng Y, Song L, Pang H, Yu R, Ding K (2016) GZD856, a novel potent PDGFR $\alpha / \beta$ inhibitor, suppresses the growth and migration of lung cancer cells in vitro and in vivo. Cancer Lett 375(1):172-178

20. Loizos N, Xu Y, Huber J, Liu M, Lu D, Finnerty B, Rolser R, Malikzay A, Persaud A, Corcoran E, Deevi DS, Balderes P, Bassi R, Jimenez X, Joynes CJ, Mangalampalli VR, Steiner P, Tonra JR, Wu Y, Pereira DS, Zhu Z, Ludwig DL, Hicklin DJ, Bohlen P, Witte L, Kussie P (2005) Targeting the platelet-derived growth factor receptor alpha with a neutralizing human monoclonal antibody inhibits the growth of tumor xenografts: implications as a potential therapeutic target. Mol Cancer Ther 4(3):369-379

21. Tap WD, Jones RL, Van Tine BA, Chmielowski B, Elias AD, Adkins D, Agulnik M, Cooney MM, Livingston MB, Pennock G, Hameed MR, Shah GD, Qin A, Shahir A, Cronier DM, Ilaria R Jr, Conti I, Cosaert J, Schwartz GK (2016) Olaratumab and doxorubicin versus doxorubicin alone for treatment of soft-tissue sarcoma: an open-label phase $1 \mathrm{~b}$ and randomised phase 2 trial. Lancet 388(10043):488-497

22. Le Cesne A, Judson I, Crowther D, Rodenhuis S, Keizer HJ, Van Hoesel Q, Blay JY, Frisch J, Van Glabbeke M, Hermans C, Van Oosterom A, Tursz T, Verweij J (2000) Randomized phase III study comparing conventional-dose doxorubicin plus ifosfamide versus high-dose doxorubicin plus ifosfamide plus recombinant human granulocyte-macrophage colony-stimulating factor in advanced soft tissue sarcomas: a trial of the European Organization for Research and Treatment of Cancer/Soft Tissue and Bone Sarcoma Group. J Clin Oncol 18(14):2676-2684

23. Rubin BP, Fletcher JA, Fletcher CD (2000) Molecular insights into the histogenesis and pathogenesis of gastrointestinal stromal tumors. Int J Surg Pathol 8(1):5-10

24. Medeiros F, Corless CL, Duensing A, Hornick JL, Oliveira AM, Heinrich MC, Fletcher JA, Fletcher CD (2004) KIT-negative gastrointestinal stromal tumors: proof of concept and therapeutic implications. Am J Surg Pathol 28(7):889-894

25. Heinrich MC, Maki RG, Corless CL, Antonescu CR, Harlow A, Griffith D, Town A, McKinley A, Ou WB, Fletcher JA, Fletcher CD, Huang X, Cohen DP, Baum CM, Demetri GD (2008) Primary and secondary kinase genotypes correlate with the biological and clinical activity of sunitinib in imatinib-resistant gastrointestinal stromal tumor. J Clin Oncol 26(33):5352-5359

26. Wagner AJ, Kindler H, Gelderblom H, Schöffski P, Bauer S, Hohenberger P, Kopp HG, Lopez-Martin JA, Peeters M, Reichardt P, Qin A, Nippgen J, Ilaria RL, Rutkowski P (2017) A phase II study of a human anti-PDGFR $\alpha$ monoclonal antibody (olaratumab, IMC-3G3) in previously treated patients with metastatic gastrointestinal stromal tumors. Ann Oncol 28(3):541-546

27. Kuznetsov G, Towle MJ, Cheng H, Kawamura T, TenDyke K, Liu D, Kishi Y, Yu MJ, Littlefield BA (2004) Induction of morphological and biochemical apoptosis following prolonged mitotic blockage by halichondrin B macrocyclic ketone analog E7389. Cancer Res 64(16):5760-5766

28. Funahashi Y, Okamoto K, Adachi Y, Semba T, Uesugi M, Ozawa Y, Tohyama O, Uehara T, Kimura T, Watanabe H, Asano M, Kawano S, Tizon X, McCracken PJ, Matsui J, Aoshima K, Nomoto K, Oda Y (2014) Eribulin mesylate reduces tumor microenvironment abnormality by vascular remodeling in preclinical human breast cancer models. Cancer Sci 105(10):1334-1342

29. Yoshida T, Ozawa Y, Kimura T, Sato Y, Kuznetsov G, Xu S, Uesugi M, Agoulnik S, Taylor N, Funahashi Y, Matsui J (2014) Eribulin mesilate suppresses experimental metastasis of breast cancer cells by reversing phenotype from epithelial-mesenchymal transition (EMT) to mesenchymal-epithelial transition (MET) states. Br J Cancer 110(6): 1497-1505

30. Cortes J, O'Shaughnessy J, Loesch D, Blum JL, Vahdat LT, Petrakova K, Chollet P, Manikas A, Diéras V, Delozier T, Vladimirov 
V, Cardoso F, Koh H, Bougnoux P, Dutcus CE, Seegobin S, Mir D, Meneses N, Wanders J, Twelves C, EMBRACE (Eisai Metastatic Breast Cancer Study Assessing Physician's Choice Versus E7389) investigators (2011) Eribulin monotherapy versus treatment of physician's choice in patients with metastatic breast cancer (EMBRACE): a phase 3 open-label randomised study. Lancet 377(9769):914-923

31. Schöffski P, Ray-Coquard IL, Cioffi A, Bui NB, Bauer S, Hartmann JT, Krarup-Hansen A, Grünwald V, Sciot R, Dumez H, Blay JY, Le Cesne A, Wanders J, Hayward C, Marreaud S, Ouali M, Hohenberger P, European Organisation for Research and Treatment of Cancer (EORTC) Soft Tissue and Bone Sarcoma Group (STBSG) (2011) Activity of eribulin mesylate in patients with soft-tissue sarcoma: a phase 2 study in four independent histological subtypes. Lancet Oncol 12(11):1045-1052

32. Schöffski P, Chawla S, Maki RG, Italiano A, Gelderblom H, Choy E, Grignani G, Camargo V, Bauer S, Rha SY, Blay JY, Hohenberger P, D'Adamo D, Guo M, Chmielowski B, Le Cesne A, Demetri GD, Patel SR (2016) Eribulin versus dacarbazine in previously treated patients with advanced liposarcoma or leiomyosarcoma: a randomised, open-label, multicentre, phase 3 trial. Lancet 387(10028):1629-1637

33. Demetri GD, Schöffski P, Grignani G, Blay JY, Maki RG, Van Tine BA, Alcindor T, Jones RL, D'Adamo DR, Guo M, Chawla S (2017) Activity of eribulin in patients with advanced liposarcoma demonstrated in a subgroup analysis from a randomized phase iii study of eribulin versus dacarbazine. J Clin Oncol 35(30):3433-3439

34. Saied A, Pillarisetty VG, Katz SC (2014) Immunotherapy for solid tumors-a review for surgeons. J Surg Res 187(2):525-535

35. Rosenberg SA, Lotze MT, Yang JC, Aebersold PM, Linehan WM, Seipp CA, White DE (1989) Experience with the use of high-dose interleukin-2 in the treatment of 652 cancer patients. Ann Surg 210(4):474-484 (discussion 484-5)

36. Bielack SS, Smeland S, Whelan JS, Marina N, Jovic G, Hook JM, Krailo MD, Gebhardt M, Pápai Z, Meyer J, Nadel H, Randall RL, Deffenbaugh C, Nagarajan R, Brennan B, Letson GD, Teot LA, Goorin A, Baumhoer D, Kager L, Werner M, Lau CC, Sundby Hall K, Gelderblom H, Meyers P, Gorlick R, Windhager R, Helmke K, Eriksson M, Hoogerbrugge PM, Schomberg P, Tunn PU, Kühne T, Jürgens H, van den Berg H, Böhling T, Picton
S, Renard M, Reichardt P, Gerss J, Butterfass-Bahloul T, Morris C, Hogendoorn PC, Seddon B, Calaminus G, Michelagnoli M, Dhooge C, Sydes MR, Bernstein M, EURAMOS-1 investigators (2015) Methotrexate, doxorubicin, and cisplatin (MAP) plus maintenance pegylated interferon alfa- $2 b$ versus MAP alone in patients with resectable high-grade osteosarcoma and good histologic response to preoperative MAP: first results of the EURAMOS-1 good response randomized controlled trial. J Clin Oncol 33(20):2279-2287

37. Chou AJ, Kleinerman ES, Krailo MD, Chen Z, Betcher DL, Healey JH, Conrad EU 3rd, Nieder ML, Weiner MA, Wells RJ, Womer RB, Meyers PA, Children's Oncology Group (2009) Addition of muramyl tripeptide to chemotherapy for patients with newly diagnosed metastatic osteosarcoma: a report from the Children's Oncology Group. Cancer 115(22):5339-5348

38. Tawbi HA, Burgess M, Bolejack V, Van Tine BA, Schuetze SM, Hu J, D’Angelo S, Attia S, Riedel RF, Priebat DA, Movva S, Davis LE, Okuno SH, Reed DR, Crowley J, Butterfield LH, Salazar R, Rodriguez-Canales J, Lazar AJ, Wistuba II, Baker LH, Maki RG, Reinke D, Patel S (2017) Pembrolizumab in advanced soft-tissue sarcoma and bone sarcoma (SARC028): a multicentre, two cohort, single-arm, open-label, phase 2 trial. Lancet Oncol 18(11):1493-1501

39. Ben-Ami E, Barysauskas CM, Solomon S, Tahlil K, Malley R, Hohos M, Polson K, Loucks M, Severgnini M, Patel T, Cunningham A, Rodig SJ, Hodi FS, Morgan JA, Merriam P, Wagner AJ, Shapiro GI, George S (2017) Immunotherapy with single agent nivolumab for advanced leiomyosarcoma of the uterus: results of a phase 2 study. N Cancer 123(17):3285-3290

40. George S, Miao D, Demetri GD, Adeegbe D, Rodig SJ, Shukla S, Lipschitz M, Amin-Mansour A, Raut CP, Carter SL, Hammerman P, Freeman GJ, Wu CJ, Ott PA, Wong KK, Van Allen EM (2017) Loss of PTEN is associated with resistance to anti-PD-1 checkpoint blockade therapy in metastatic uterine leiomyosarcoma. Immunity 46(2): 197-204

41. D'Angelo SP, Mahoney MR, Van Time BA et al (2017) A multicenter phase II study of nivolumab \pm ipilimumab for patients with metastatic sarcoma (Alliance A091401) (abstract). J clin oncol 35(suppl; abstr 11007). Abstract available online at http://abstr acts.asco.org/199/AbstView_199_184079.html. Accessed $13 \mathrm{Jul}$ 2017 